\title{
LA GENERIZACIÓN DE LOS CUERPOS EN PERSPECTIVA HISTÓRICA: UNA MIRADA DESDE LAS PRÁCTICAS CORPORALES DE LAS MUJERES
}

\author{
GENDERING OF BODIES IN HISTORY: A LOOK FROM THE CORPORAL PRACTICES OF WOMEN
}

\section{A GENERIZAÇÃO DOS CORPOS EM PERSPECTIVA HISTÓRICA: UM OLHAR DESDE AS PRÁTICAS CORPORAIS DAS MULHERES}

\author{
Laura Marcela Méndez ${ }^{1}$ \\ Pablo Ariel Scharagrodsky²
}

\section{Resumen}

Este trabajo tiene como objetivo central historiar las prácticas corporales y las instituciones de tiempo libre que acompañaron la cotidianeidad de niñas y jóvenes en la primera mitad del siglo xx en la Argentina. Se analiza un conjunto de operaciones simbólicas que prescribieron prácticas corporales para las mujeres atravesadas por el higienismo y un discurso médico masculino impregnado de ideas positivistas, eugenésicas y evolucionistas. Se adopta una perspectiva regional (cuyo foco es la Patagonia norte) y de género. Se resalta el entramado de relaciones sociopolíticas, culturales y educativas que, accionado tanto desde el Estado como desde la sociedad civil, produjo procesos de generización corporal y tensionó procesos de territorialización, fronterización y nacionalización. Asimismo, se puntualiza en las instituciones, políticas y mecanismos implementados para la educación corporal de la infancia y de la juventud, en pos de la modelización y generización de cuerpos-sujetos. El estudio se propuso desplegar una cartografía de la participación de niñas y jóvenes en prácticas deportivas y de escautismo con el fin de ejemplificar cómo estos aprendizajes no se construyeron sobre los cuerpos sino en los cuerpos, permaneciendo en ellos como marcas indelebles en la configuración de subjetividades.

Palabras clave: prácticas corporales; géneros; instituciones; historia regional; Estado; Patagonia

\section{Abstract}

The main purpose of this article is to study the corporal practices and the free time institutions that accompanied the daily lives of girls and young women during the first half of the twentieth century in Argentina. It analyzes a set of symbolic operations that prescribed a number of corporal practices for women, influenced by hygienism and a male medical discourse impregnated with positivist, eugenic and evolutionist ideas. A genre and regional perspective (focused on Northern Patagonia) is adopted. We highlight the framework of socio-political, cultural and educational relations that, driven both by the State and civil society, led to processes of corporal generalization and put a strain on the territorialization, frontierization and nationalization processes. We also stress on the institutions, policies and mechanisms implemented for the corporal education of infancy and youth, aimed at modelling and gendering bodies-subjects. The study sought to map the participation of girls and young women in sports and scouting practices in order to exemplify how these learnings were not built over the bodies but on the bodies, where they remained as indelible marks in the configuration of subjectivities.

Keywords: corporal practices; genders; institutions; regional history; State; Patagonia

1 Unidad Ejecutora en Red. Cehir-Ishir-Conicet-Nodo Comahue. Universidad Nacional del Comahue. Centro Regional Universitario Bariloche. Correo electrónico: lauramendezbari@gmail.com.

2 Universidad Nacional de Quilmes. Universidad Nacional de La Plata. Correo electrónico: pas@unq.edu.ar. 
Este trabalho visa historias as práticas corporais e as instituições de tempo livre que estão presentes no dia-a-dia de crianças e jovens mulheres na primeira metade do século XX na Argentina. Analisa-se um grupo de operações simbólicas que prescreveram práticas corporais para as mulheres atravessadas pelo higienismo e um discurso médico masculino impregnado de ideias positivistas, eugenésicas e evolucionistas. Adota-se uma perspectiva regional (cujo ênfase é Patagônia Norte) e de gênero. Assinala-se a estrutura de relações sociopolíticas, culturais e educativas que, atuando tanto desde o Estado como desde a sociedade civil, produziu processos de generização corporal e problematizou processos de territorialização, fronteirização e nacionalização. Igualmente, se faz ênfase nas instituições, políticas e mecanismos implementados para a educação corporal da infância e da juventude, para atingir a modelização e a generização de corpos-sujeitos. 0 estudo teve como propósito desenvolver uma cartografia da participação de crianças e jovens mulheres em práticas esportivas e de escautismo com o fim de exemplificar como estas aprendizagens não constituíram sobre os corpos senão nos corpos, permanecendo neles como marcas indeléveis na configuração de subjetividades.

Palavras chave: práticas corporais; géneros; instituições; história regional; Estado; Patagônia

Fecha de recepción: 13 de julio de 2016

Fecha de aprobación: 7 de febrero de 2017

Para citar este artículo:

Méndez, L. y Scharagrodsky, P. (2017). La generización de los cuerpos en perspectiva histórica: una mirada desde las prácticas corporales de las mujeres. Lúdica Pedagógica, (25), 47-60. 
La corporalidad y su materialidad desplegada en las prácticas corporales muestran las formas de interacción entre las personas y el entorno natural y social, así como permean las relaciones de lenguaje, poder y trabajo. El cuerpo, concebido como una construcción simbólica y cultural, las representaciones y los saberes que sobre él se erigen son tributarios de un momento histórico, de un "lugar" y de una visión del mundo. La temporalidad y, por ende, la historia, son constitutivas del sujeto-cuerpo y de los significados que sobre él se construyen a través del lenguaje.

En el interés de dar cuenta de estos procesos, en los últimos treinta años han surgido perspectivas renovadas en el campo historiográfico argentino que generan estudios vinculados a las prácticas corporales -la etnomotricidad, la ludicidad, los deportes- y a la historia del tiempo libre y de la educación física.

En este marco, este trabajo tiene como objetivo central historiar las prácticas corporales y las instituciones de tiempo libre que acompañaron la cotidianeidad de niñas y jóvenes en la primera mitad del siglo xx, desde una perspectiva regional -cuyo foco es la Patagonia nortey de género. Nos interesa particularmente analizar el entramado de relaciones socio-políticas, culturales y educativas, que accionadas tanto desde el Estado como desde la sociedad civil, produjeron procesos de generización corporal y tensionaron procesos de territorialización, fronterización y nacionalización con el fin de integrar el espacio patagónico a un Estado nacional, así como las instituciones, las políticas y los mecanismos implementados para la educación corporal de la infancia y de la juventud, transmisores de valores y pautas en pos de la modelización y generización de cuerpos-sujetos.

Nuestro propósito nos conduce a analizar un conjunto de operaciones simbólicas que prescribieron qué prácticas corporales fueron habilitadas para las mujeres y cuáles no, y cómo en estas impactaron el higienismo y un discurso biomédico masculino, impregnado de ideas positivistas, eugenésicas y evolucionistas. No es nuestra intención profundizar cada uno de los aspectos mencionados -sería imposible dada la extensión del trabajo-, sino reconstruir la participación de niñas y jóvenes en prácticas deportivas y de escoutismo con el fin de ejemplificar cómo estos aprendizajes no tuvieron lugar sobre los cuerpos sino en los cuerpos, y permanecieron en ellos como marcas indelebles en la configuración de ciudadanías e identidades.

\section{NACIÓN, GÉNERO Y LAS PRÁCTICAS CORPORALES}

Las propuestas alberdianas de ampliar la población de la joven Argentina mediante un proceso migratorio de carácter masivo en las últimas décadas del siglo XIX produjo, entre sus efectos, algunos no deseados, tanto en el plano material (heterogeneidad étnica, problemas urbanos) como en el ideológico (ideologías que cuestionaban las formas hegemónicas del poder).

La llamada "cuestión social" (Suriano, 2000; Zimmerman, 1995), que tuvo su inicio en la década de 1860, se preocupó, en una primera instancia, por los cambios producidos en el país por la inmigración masiva en relación con el crecimiento de las ciudades, las cuestiones sanitarias y las identitarias. En el albor del nuevo siglo, la preocupación se centró en la cuestión obrera y las ideologías que amenazaban subvertir el orden social imperante. En un contexto signado por la efervescencia política y social, el Estado argentino esgrimió una política dual: sin dejar de representar los intereses de la clase hegemónica y ejercer una política represiva para aislar y erradicar a los sectores más contestatarios, orientó su política hacia la búsqueda de formas de dominación más legales, organizadas y eficaces, y se propuso el desarrollo de políticas preventivas e integradoras.

Distintas perspectivas del movimiento eugenésico nacional interpelaron la amenaza de la degeneración racial en la Argentina cosmopolita y multicultural de las primeras décadas del siglo xx e intentaron brindar soluciones científicas a problemas como los de la raza, la herencia, el decadentismo y el degeneracionsimo. Propusieron un conjunto de medidas destinadas a paliar esta situación, sostenidas, en su mayoría, en la capacidad que poseía el medio social para transformar a los sujetos (Palma, 2005).

A través de un entramado de ideas que vinculaban el discurso médico (basado en principios eugenésicos, otros provenientes del darwinismo social y la biotipología) con las políticas públicas y la razón de Estado, se construyó "científicamente" una idea de la otredad que trajo como correlato la descalificación y la segregación en virtud de características corporales, sociales, 
religiosas, culturales o vinculadas con el género o con el comportamiento sexual. Concomitantemente, el higienismo puso énfasis en los factores ambientales que podían causar enfermedades -entendidas como sociales (Armus, 2000)-y producir efectos nocivos sobre la futura descendencia, en la convicción de que una adecuada política sanitaria podía prevenir muchos de ellos.

Un heterogéneo grupo de liberales reformistas, utilizando como cánones interpretativos el modernismo cultural y el positivismo, idearon itinerarios de acción que pretendían transformar a los pobladores de Argentina en ciudadanos que se identificaran con el Estado-nación y adquirieran -a partir de una actualización de ciertas trayectorias del pasado y un ambiente natural-social propicio- un conjunto de principios y virtudes que posicionaran al país como líder de la América del Sur. Al servicio de este arbitrario cultural, un conjunto de instituciones se propusieron construir, desde la Argentina profunda, el germen de una nacionalidad que, confiada en el Ejército y en el electorado nacional, escapase del fantasma de la degeneración y formara "un hombre nuevo". Para que este se hiciese posible, era necesario comenzar con la transformación de la niñez y de la juventud.

Este proyecto se materializó en un proceso con trayectorias diferenciadas, ya se tratara de hombres o de mujeres. Si bien ambos participaron del ideal nacionalizador, la propia idea de nación y nacionalismo fue mutando a la par del avance del siglo xx, y la agenda normativa, axiológica y práctica se constituyó, desde su germen, como sexuada.

La escuela fue utilizada como factor clave para imponer una higiene de base científica y con un alto contenido moral en la población de sectores populares. Las instituciones educativas tuvieron como misión formar en el paradigma de la nacionalidad argentina, a la vez que un conjunto de prescripciones aportaron a la construcción de un tipo de varón y de un tipo de mujer que garantizarían la reproducción material y simbólica de la modernidad. Si bien la docencia fue una profesión femenilizada y feminizada, quienes tomaron las decisiones sobre qué y cómo enseñar fueron, hasta avanzado el siglo Xx, varones abogados y médicos, títulos preponderantes en la constitución de los cargos jerárquicos en materia educativa.

En ese proceso de significación, la subjetividad femenina hegemónica se construyó, como señala Marcela Nari (1995 y 2004), sobre la base de un "instinto maternal", sostén necesario de la familia nuclear, la división sexual del trabajo y la sujeción de las mujeres al ámbito doméstico. Para aquellas que trabajaban en el ámbito extradoméstico, las profesiones afines a las técnicas de cuidado, como la enfermería y el magisterio, las visitas domiciliarias y la asistencia social, les permitieron desarrollar lo que en ellas era innato: su sentir de madres.

En el caso del varón hegemónico, se aspiró al autocontrol, la robustez y la fuerza en la educación del ciudadano soldado que debía garantizar a través de su formación corporal, la capacidad de defensa de la patria ante agresiones tanto internas como externas.

Así, instituciones estatales y civiles (escolares y extraescolares) fomentaron cierto tipo de prácticas que tuvieron mayoritariamente la función de contribuir a los mandatos hegemónicos de un hombre-soldado-viril y una mujer madre-cuidadora-femenina, las cuales actuaron como "refuerzo" del proceso de normalización y homogeneización social, a la vez que de diferenciación genérica.

Uno de los discursos que reforzó la binariedad y jerarquización de roles, propiedades y funciones para cada colectivo fue el registro médico. Este se convirtió en legitimador de posibilidades motrices, gestuales, cinéticas (así como educativas, morales, sexuales y políticas) bajo un supuesto halo de neutralidad, atravesado por una determinada concepción sobre la diferencia sexual. La descripción de los cuerpos -huesos, músculos, ligamentos, tendones, órganos, fluidos, sistemas funcionales, etc.- estuvo históricamente atravesada por una determinada conceptualización sobre la diferencia sexual que excluía y, al mismo tiempo, prescribía la oferta gímnica y deportiva para varones y mujeres, o mejor dicho, para construir masculinidades y feminidades. Lentamente se ligaron imaginaria -y arbitrariamente- ciertos gestos, desplazamientos, movimientos, saltos, posturas y deportes dependiendo del "sexo" anatómico y también de la edad, la clase social, la "raza", el color de piel, la religión, la orientación sexual, entre otros. Una nueva profesión que se consolidó entre los años veinte y treinta avaló este proceso de generización y sexualización: el médico deportólogo (Scharagrodsky, 2015). Durante buena parte del siglo xx los mandatos científicos y ciertas profesiones justificaron la prescripción de la gimnasia rítmica, la pelota al cesto, el tenis y el softball para las mujeres, mientras que para los varones se indicó la práctica de la gimnasia con aparatos, el básquetbol, el rugby, el béisbol, la esgrima, el boxeo y el fútbol. Ciertamente 
estas prácticas deportivas contribuyeron a masculinizar y feminizar los cuerpos, instalando un conjunto de sentidos, significados, metáforas, metonimias y representaciones sobre la diferencia sexual.

\section{INSTITUCIONES, CORPORALIDAD Y DEPORTES DESDE UNA PERSPECTIVA DE GÉNERO}

El análisis de las instituciones como ámbitos de sociabilidad, entendidos como espacios de interacción social que se revelan en un tiempo y en un espacio, permite realizar inferencias acerca de la vida cotidiana, los lugares de encuentro, los modos de relacionarse y las representaciones sociales complejas y variadas, a la vez que habilita el estudio de la vida privada de los sujetos que se auto-construyen públicamente en las prácticas y en los discursos.

En otros trabajos vinculados a la historia de los cuerpos y las prácticas corporales (Méndez, 2011; Podlubne, 2015) hemos analizado cómo las instituciones educativas formales y, dentro de ellas, la enseñanza de prácticas corporales y deportivas, contribuyeron a la construcción de un determinado tipo de feminidad y masculinidad en la Argentina finisecular y durante las primeras décadas del siglo Xx. En esta instancia, centraremos nuestro análisis en instituciones extraescolares vinculadas a las prácticas corporales y deportivas. Entre ellas, focalizaremos la mirada en la institución scout argentina y los clubes deportivos de la Patagonia norte.

El deporte moderno comenzó a practicarse en Argentina a fines del siglo XIX, en pleno proceso de afianzamiento del Estado nacional y del modelo económico agroexportador portuario. Si bien la colectividad inglesa no fue significativa en cuanto a número de inmigrantes, fue muy importante como mano de obra calificada para la construcción de los ferrocarriles que debían conectar los campos y ciudades del interior con el puerto de Buenos Aires, y como promotora de ciertos deportes en el escenario nacional. Esgrima, fútbol, remo, entre otros, fueron prácticas ligadas íntimamente a colegios o clubes de esa colectividad, mientras que otros deportes tuvieron en sus iniciadores a inmigrantes italianos (como en el caso del ciclismo), suizos (el tiro) y de la Europa nórdica (en esquí).

Principios eugenésicos, higiénicos y normalistas a los que ya aludimos también tiñeron las concepciones sobre los deportes en Argentina de las primeras décadas del siglo Xx. Las arengas a favor del deporte -asociadas al discurso médico y al mejoramiento de la raza ${ }^{3}$ - establecían que no todos los deportes podían ser practicados por niñas y jóvenes, y que no todas las niñas y jóvenes podían practicar deportes. La etnia, la edad, la condición social y familiar fueron algunas de las cuestiones que definieron que prácticas corporales podían realizar las mujeres sin temor de masculinizarse, perder la honra y someterse a la condena social.

Renombrados fisiólogos e higienistas, especialmente franceses, contribuyeron a legitimar las diferencias entre varones y mujeres en cuanto a su estructura anatómica, orgánica y funcional, jerarquizando lo masculino por sobre lo femenino. Uno de los que más impacto tuvo en nuestro país fue Fernand Lagrange (1845-1909) quien investigó los efectos del ejercicio físico sobre el organismo humano. En un entramado de cuestiones higiénicas, biológicas, sociales y morales, este autor planteó que las aptitudes físicas eran jerárquicamente diferentes entre varones y mujeres.

Lagrange y Ángelo Mosso naturalizaron no solo la debilidad anatómica (esquelética, muscular o articular), sino también la fisiológica. Todos los procesos y funciones del cuerpo femenino eran potencialmente más débiles: su sistema nervioso, su sistema circulatorio y su sistema respiratorio. Su sistema nervioso era más propenso a la impresionabilidad y a la sensibilidad así como a la excesiva movilidad del carácter, al apasionamiento, al desequilibrio nervioso, a las convulsiones y a los súbitos cambios de carácter, lo que podía desembocar en la histeria, verdadera epidemia a finales del siglo XIX. De igual manera, los sistemas circulatorio y respiratorio eran más proclives a perder la energía necesaria para la conservación del equilibrio fisiológico interno, con los peligros que ello acarreaba para la perpetuidad de la futura "raza" argentina. Asimismo, su sistema digestivo presentaba mayores índices de enfermedades vinculadas a la función de nutrición (dispepsias, constipaciones, dolores estomacales, insuficiencias digestivas, perezas estomacales, obesidades de todo tipo, etc.). Por último, el sistema reproductivo debía ser cuidadosamente tratado, y controlado, ya que su fragilidad física podía poner en riesgo a la descendencia

3 El término raza implica múltiples sentidos y significados, en cuanto su polisemia y diversidad de uso según los contextos de enunciación. 
y el futuro de la nación. En nombre de dichas debilidades -imaginadas y deliberadamente fabricadas- se justificaron y legitimaron otro tipo de fragilidades y debilidades sociales, económicas y, muy especialmente, políticas, las cuales circularon y se transmitieron en la trama escolar (Barrancos, 2007; Lavrin, 1998; Nari, 1995). A pesar de que estas lógicas argumentativas fueron predominantes, en su interior existían una serie de resistencias, ambigüedades y contradicciones, entre ellas las vinculadas con el supuesto "destino" maternal, ya que ¿cómo se podía aceptar la supuesta fragilidad y debilidad de un ser que iba a dar vida y asegurar el futuro de la nación?, o ¿por qué tolerar ciertas prácticas físicas para las mujeres obreras que contradecían el propio discurso anatomo-fisiológico?

Más allá de estas contradicciones, ambivalencias y paradojas, la teoría fisiológica de la fatiga elaborada por Ángelo Mosso (1846-1910), en parte defendida por Lagrange, justificó las menores posibilidades físicas y orgánicas de las niñas y de las mujeres así como la exclusión en el acceso a un enorme universo de prácticas. El razonamiento fue que sobrecargar la "natural" debilidad de las niñas y las mujeres con ciertas actividades y tareas corporales dañaría la economía física y orgánica de sus cuerpos, lo cual generaría graves perjuicios en la descendencia o, lo que era peor, desdibujaría su función sexual ya que podía virilizarlas. Además, la debilidad fisiológica acrecentaba la excitabilidad nerviosa, fomentando la histeria e inclusive la lujuria y las posibles e inaceptables "tempestades" sexuales. Todo ello producía mayores grados de debilidad (Mosso 1892, p. 364; Mosso, 1894; Lagrange, 1894). Ciertamente, la cuestión central no fue negar la actividad física a las niñas, sino generar un conjunto preciso de recaudos, todos ellos anclados en una clara base moral. En este punto la moderación se convirtió en el regulador principal de las prescripciones físicas (Scharagrodsky, 2014).

La supuesta debilidad fisiológica de las niñas y de las mujeres justificó la proscripción de los ejercicios de resistencia y en general todos los fatigantes, por ser considerados perjudiciales para ellas en todas las edades. Los argumentos fueron circulares. El supuesto sobre la aplicación de una menor intensidad en la ejercitación física "femenina” justificó y naturalizó la imposibilidad física y orgánica como un hecho y no como producto del propio discurso originado en la teoría de la fatiga.
La economía de la fatiga física en las niñas fue un precepto que debía primar en cualquier ejercicio físico o clase de gimnasia. Realizar esfuerzos musculares intensos y violentos "sería forzar su naturaleza" (Lagrange, 1894, p. 147). Malgastar la energía "femenina” podía comprometer no solo a la niña, sino su futura capacidad reproductiva, generando en algunos casos estados indeseables como la esterilidad. El desarrollo "excesivo" de la fuerza en las niñas no estaba permitido, ya que se suponía que atentaba contra el normal funcionamiento fisiológico de su cuerpo.

Es preciso descartar, de la gimnasia de las jóvenes todos los ejercicios que no tiendan más que a desenvolver los músculos; estos ejercicios serían inútiles: estarían mal adaptados á la estructura de la mujer y á sus aptitudes físicas. Tendrían además otro inconveniente grave: el de producir deformaciones que alteran la elegancia de las formas. (Lagrange, 1894, p. 149).

Detrás de estos temores estaba el miedo a que las niñas se virilizaran y perdieran su "natural" encanto y belleza (construida desde una mirada heteronormativa deseante), así como todas las cualidades supuestamente femeninas: recato en los movimientos, decoro en la marcha, suavidad en los saltos, gracia en los ejercicios físicos, entre otras. De hecho, salvo algunas excepciones, la práctica deportiva fue cuestionada en las niñas, más por razones morales que orgánicas.

De igual manera, los espacios ideados para las prácticas de la educación física estuvieron atravesados por estos principios y teorías. En nombre de la diferencia corporal asociada con una supuesta inferioridad, fragilidad o deficiencia del cuerpo femenino se prescribieron y naturalizaron menores dimensiones espaciales para la práctica de juegos y ejercicios físicos dirigidos a las niñas, así como menores tamaños y pesos de los materiales que utilizaban. Muchas veces, siguiendo la supuesta menor capacidad de resistencia a la fatiga en las niñas se asignó un metraje menor en los patios de las escuelas y en las dimensiones de los campos de juego. Por ejemplo, siguiendo la supuesta menor capacidad de ejercicio de fuerza se estableció en el reglamento del "juego de pelotas" practicado en muchas instituciones educativas argentinas que: "el peso de la pelota será de 750 a 800 gramos, con una circunferencia de 0,50 a $0,55 \mathrm{~ms}$. para los varones; de 550 a 600 gramos y 
una circunferencia de 0,45 a 0,50 ms. para las niñas" (Romero Brest, 1922, p. 62). Lo mismo sucedía con los cestos cuando se reglamentó el juego de pelota al cesto: "3 metros de altura para los partidos de las señoritas y 3,50 metros para los varones" (p. 76).

La "natural" debilidad de sus músculos, huesos, tendones, órganos y funciones fue el axioma que autolegitimó la diferenciación de actividades, espacios y métodos. $\mathrm{Al}$ no objetarse dicho axioma, se validó la diferencia como sinónimo de jerarquía y desigualdad:

El ejercicio no es menos necesario á las muchachas que á los muchachos. Pero hay demasiadas diferencias entre ambos sexos, desde el punto de vista de la forma, de la estructura general del cuerpo y sobre todo del de ciertas funciones especiales, para que sea posible aplicarles los mismos métodos. (Lagrange, 1894, p. 144).

En concordancia con estos postulados, ya desde los albores del siglo xx y de la mano de Enrique Romero Brest, figura central, creador y difusor del Sistema Argentino de Educación Física, la visión sobre la mujer y las prácticas corporales estuvo fuertemente delimitada por una mirada masculina falologocéntrica. La propuesta "romerista", en principio más abarcadora que las existentes en el periodo señalado por su decidido apoyo a la inclusión de las niñas y mujeres en el campo de la educación física, no dejó de cultivar la feminidad tradicional y la maternidad como uno de los destinos más importantes, ya que no cuestionó la posición femenina biológicamente determinada, no objetó la estética femenil dominante, ni puso en tela de juicio su papel maternal o sus "naturales" condiciones femeniles ${ }^{4}$.

La política corporal elaborada e implementada por Romero Brest tuvo un papel significativo en el universo escolar -nivel elemental, colegios nacionales y escuelas normales- y contribuyó a difundir y transmitir ciertos ideales femeniles en el campo gímnico y deportivo. Con relación al universo femenino, si bien Romero Brest fue un fuerte defensor de la inclusión de las niñas y mujeres en la educación física escolar, con lo cual acrecentó las posibilidades físicas de estas y las animó a ser más activas en el plano físico -activas y dinámicas, pero

4 En las primeras décadas del siglo XX algunas feministas de la primera ola, socialistas militantes, anarquistas, librepensadoras y pedagogas escolanovistas tensionaron, erosionaron y cuestionaron parte de los guiones femeninos tradicionales. moderadas y respetuosas ante los opresivos ideales estéticos-. Su sistema de educación corporal contribuyó a establecer el ideal femenino vinculado estrechamente con la maternidad y con cierta forma de entender la femineidad. Al respecto, el sentido de la femineidad en los ejercicios físicos, en los juegos y en la gimnasia debía incardinar ciertos valores y cualidades morales como el decoro, el pudor, la gracia, el recato, la serenidad, la delicadeza y la elegancia en los movimientos. Para lograr este cometido se prescribieron en las niñas y mujeres ejercicios físicos que les dieron un rol esencial a la pelvis y el abdomen, y se estimularon algunas capacidades físicas: velocidad y, con ciertas reservas, la fuerza. Asimismo, se proscribieron los ejercicios de resistencia -y en general todos los fatigantes- en las niñas, con lo cual se limitó un conjunto de posibilidades y experiencias corporales considerados como exclusivamente "masculinos".

En esta línea de argumentación, algunas prácticas corporales fueron visualizadas como posibles terapias con el sentido de recuperar el orden y equilibrio orgánico de distintas anomalías, en particular en los casos de histeria $^{5}$. La gimnasia femenina, las actividades recreativas al aire libre, en especial los paseos en bicicleta, fueron los más recetados para el universo de las mujeres.

En el caso de los deportes, se osciló entre la negación de participación femenina en las actividades deportivas -asociando a la "mujer atlética" con la pérdida de la femineidad, sinónimo de hombruna, y la fertilidad- y la aceptación, y aun promoción de ciertos deportes. Existió una sistemática proscripción para las mujeres con relación a capacidades motoras como la resistencia y la velocidad, y deportes como el atletismo, el fútbol y el boxeo. Para los hombres, en cambio, las capacidades promovidas fueron la fuerza, la resistencia y la velocidad, lo que les permitió la participación en todos los deportes existentes (Scharagrodsky, 2006).

Los argumentos que vinculaban al deporte como medio idóneo para mejorar la productividad del trabajador, la eficacia y eficiencia laboral, no se pusieron en juego

\footnotetext{
5 La histeria, como enfermedad específicamente de las mujeres causada por un órgano de origen sexual imputable al útero, con variada sintomatología orgánica, actitudinal y emocional, sirvió no sólo para controlar la vida de las mujeres sino también para contrastar un modelo único de masculinidad normativa. Recomendamos para este aspecto la lectura de Pablo Scharagrodsky (2006).
} 
en las primeras décadas del siglo xx para alentar las prácticas deportivas en las mujeres, por cuanto estas entraron solo tardíamente al trabajo fabril, siempre en una posición subordinada -tanto en lo salarial como en las responsabilidades- a las de sus jefes varones. Por otro lado, los trabajos "naturales" para la condición femenina, como los asociados a las técnicas del cuidado (la vocación docente, religiosa o la vinculada al cuidado de los enfermos y la promoción de la salud) y los trabajos en los que las mujeres abundaban -como en el caso de las telefonistas y las trabajadores textiles-requerían ciertas actitudes, voluntades y algunos contenidos teórico-prácticos que se priorizaron por sobre la resistencia y las capacidades físicas.

Este conjunto de consideraciones son las que permiten explicar por qué en las primeras décadas del siglo Xx las mujeres no participaron de las prácticas del fútbol, lo hicieron en forma diferenciada de los varones en el caso del ciclismo y el scoutismo, y fueron sus pares en el caso del esquí. La Norpatagonia es el escenario para desplegar estas argumentaciones.

\section{PRÁCTICAS DEPORTIVAS Y MUJERES. UNA MIRADA DESDE EL PAÍS DEL VIENTO}

Hemos elegido a la Norpatagonia como el espacio en el cual anclar algunas experiencias vinculadas a las prácticas corporales y deportivas en la primera mitad del siglo Xx, desde una perspectiva de género.

Un lento y discontinuo proceso de urbanización incorporó en segmentos del espacio patagónico modos de vida modernos y urbanos, tras la finalización de la ocupación militar violenta acaecida en los años 1880. En el caso de la Patagonia norte, estas comunidades se conformaron con un sustrato indígena y chileno al que se le sumaron contingentes migratorios europeos. Circuitos mercantiles asociados a mercados y puertos de Chile, producción ganadera en el espacio rural y promoción del turismo en espacios con un paisaje privilegiado constituyeron la trilogía sobre las que desarrollaron las actividades económicas y sociales.

El pluralismo cultural producto de la heterogeneidad de origen trajo aparejado, entre otras cuestiones, la proliferación de ciertas prácticas deportivas, muchas de ellas asociadas a historias vitales previas a la radicación de los contingentes en la región y a la similitud del paisaje con las regiones de procedencia, el gusto por las actividades físicas en el entorno natural y un tiempo disponible para dedicarse al esparcimiento. Fueron los ámbitos de sociabilidad en los que se desenvolvió parte de la vida cotidiana y se reprodujeron las representaciones sociales que se iban construyendo, formando un ámbito propicio para la germinación y transmisión de la cultura y sus prácticas.

Fútbol, ciclismo, tiro de fusil, pelota paleta, actividades de montaña, carreras, ajedrez, boxeo, básquetbol, automovilismo, entre otras, fueron las propuestas para el tiempo de ocio. Algunas de estas actividades se organizaron en clubes o instituciones que les dieron un marco más formal. Fue durante las décadas de los 30 y los 40, cuando las actividades corporales, recreativas o deportivas comenzaron realmente a visibilizarse con más fuerza. La sociedad civil local las promovía y apoyaba desde la prensa local y regional.

Vecinos construyeron lentamente grupos sociales de pertenencia desde los cuales empezaron a desarrollar actividades sociales y culturales y se constituyeron clubes en torno a una práctica deportiva que tuvieron un rol muy importante en la construcción de identidades regionales. En gran medida, los actores sociales que las practicaban se relacionaban con actividades comerciales -como dueños o empleados-, con la obra pública o eran empleados estatales. Sus obligaciones cotidianas les permitieron contar con un tiempo disponible para organizar y participar de las recreaciones y deportes. Estas, a excepción del boxeo y el ajedrez, se materializaban generalmente en espacios al aire libre, por lo que las cuestiones climáticas marcaban la agenda. Autoridades políticas, educadores y prensa local y regional propiciaban la práctica de ejercicios físicos concebidos como garantes de la salud física y como fortalecedores del carácter ${ }^{6}$.

Tres prácticas corporales (el ciclismo, el fútbol y el esquí) se destacaron en las primeras décadas del siglo por el número de practicantes, sus procesos de deportivización e institucionalización y, en el caso de esquí, por el aditamento de constituirse como un bien turístico que

6 Los periódicos regionales La Nueva Era (Viedma), Río Negro (General Roca) y El Territoriano(Neuquén) dan cuenta de estas afirmaciones, así como los discursos pronunciados durante el periodo territoriano por gobernadores y funcionarios estatales de los ámbitos de la salud y la educación. 
atraía a visitantes en el periodo invernal cordillerano ${ }^{7}$. En paralelo, la práctica del scoutismo se consolidó en la Patagonia como la mayor institución de tiempo libre de niños y jóvenes. Analizaremos brevemente cada una en clave de género.

En buena parte del país, el vertiginoso crecimiento del fútbol generó reacciones variadas. Hubo empresarios iluminados que veían allí un ingrediente del Estado de bienestar que querían desarrollar. Hubo directivos de clubes que exaltaron sus virtudes higiénicas y viriles. Hubo pedagogos de Estado que alertaron sobre la violencia física y moral que generaba dicha práctica. Hubo voces críticas, fervientemente opuestas al creciente profesionalismo que ya impregnaba la práctica de este deporte. Hubo sectores de izquierda que pretendiendo hablar en nombre de los obreros alentaban ligas de fútbol alternativo. Hubo otros sectores de izquierda que, por el contrario, lo combatían con ferocidad por ver allí una suerte de opio que disminuía la potencialidad revolucionaria de los trabajadores. Y hubo reacciones variadas -cambiantes en el tiempo-por parte de los educadores físicos (Armus y Scharagrodsky, 2014). En cualquier caso, y más allá de las variadas y matizadas reacciones de diferentes actores sociales, dependiendo del lugar geográfico, la ideología, el sector social, el género, la profesión, etc., el fútbol (profesional o recreativo) se convirtió en una práctica masculina masiva en buena parte del país durante la primera mitad del siglo xx (Archetti, 2003; Chiappe, 2015; Frydenberg, 2011; Reyna, 2014; Roldan, 2015) y fue construyendo un estereotipo masculino dominante que contribuyó a construir un cierto ethos masculino, una determinada moral sexual, una estética viril, una específica definición física del cuerpo masculino en movimiento y de algunas de sus partes y un sentido particular de lo "nacional". Estos sentidos fueron variando a lo largo del siglo $\mathrm{xx}$ delimitando claramente los cuerpos masculinos abyectos: afeminados, cobardes, pusilánimes, maricones, torpes, tímidos, etc. Parte de estos sentidos estuvieron ligados imaginariamente al universo femenino como

7 Los comentarios sobre estos tres deportes surgen de los resultados de investigación de los colegas del Cehir, sede Bariloche, en el marco del proyecto "Instituciones, prácticas corporales y tiempo libre". Los aportes de Adriana Podlubne (2015) sobre ciclismo, Mariano Chiappe sobre fútbol (2015) y María Chiocconi sobre el esquí (2011 y 2015) constituyen el sostén de estas reflexiones. límite simbólico y material que no se debía cruzar. El fútbol en la Norpatagonia, con matices, también participó de este proceso.

En las jóvenes y escasas ciudades que fueron construyéndose a la par del avance de los procesos de institucionalización y control del Estado nacional, el fútbol pronto se convirtió en el deporte más practicado. Su práctica tuvo un carácter corporal y social exclusivamente masculino, que hacía eco de los ideales de fuerza, virilidad y hombría de la época. El sujeto ciudadano y masculino se afianzó fuertemente con la ayuda del fútbol practicado, desarrollado y organizado -incluso en las comisiones directivas de los clubes- exclusivamente por hombres. Su práctica materializaba el ideal de una masculinidad excluyente que veía con disgusto muestras de debilidad y fragilidad, sentenciándolas como cosas de mujeres.

Si bien los primeros clubes de fútbol datan de comienzos del siglo xx, fue en la década de 1930 cuando proliferaron y aumentaron la cantidad de equipos y las competencias. A diferencia de otras actividades de tiempo libre en las que gobernantes e instituciones del Estado tuvieron gran injerencia, el fútbol se generó y desarrolló de manera más espontánea, de la mano del crecimiento poblacional urbano y de la conformación de sectores medios y medios-bajos de trabajadores que participaron de esta práctica en procura de recreación, identificación grupal y reconocimiento social.

Una nutrida agenda de competencias y encuentros, que se alternaban con partidos organizados en función del calendario festivo regional, favoreció la competencia entre diferentes clubes, que por lo general representaban a países de origen o comunidades laborales. En ellos las mujeres eran espectadoras, que desde improvisadas tribunas alentaban a algún varón miembro del grupo familiar. No participaban ni del deporte ni de los clubes que se organizaron en torno a él, a excepción de alguna velada danzante, en carácter de festejo o en procura de juntar fondos.

En el caso del ciclismo, las prácticas ciclísticas se promovieron desde los inmigrantes, en su mayoría italianos, que dieron origen a los primeros clubes de ciclismo y las bicicleterías, que proponían un cronograma de actividades a la vez que ofrecían equipos, repuestos, reparación y asesoramiento. La topografía del entorno natural fue concebida en términos de desafío a cumplir, en el lema "Conocer para dominar". En ese marco se 
exploraron zonas vírgenes y se desafió la geografía del terreno y el clima, de la mano del ejercicio y esfuerzo físico, en conjunción con la creatividad tecnológica y la belleza paisajística. El cronograma de carreras vinculó ciudades y regiones y estuvieron circunscriptas -salvo contadísimas excepciones- a los varones, mientras el uso de la bicicleta en las mujeres estuvo más relacionado con los paseos y excursiones familiares o en función de recomendaciones médicas, como práctica de gimnasia respiratoria y gimnasia terapéutica. En el caso de que se propusieran carreras para mujeres, estas tenían menor frecuencia, duración y grado de complejidad que las organizadas para los varones.

Una cuestión presente en el momento de la exclusión de las mujeres en las prácticas futbolísticas y ciclísticas es la vestimenta. La ligazón entre vestido, apariencia corporal y cuestión moral determinó en los comienzos del siglo Xx qué cosas podían usarse y qué no, de acuerdo a cánones estéticos e higiénicos, que asociaban apariencia con esencia. Para andar en bicicleta las mujeres tenían que realizar dos conductas contrarias a la moral de época: abrir las piernas y abandonar las faldas para impedir un mal mayor: que pudiera verse su ropa interior. En el caso del fútbol, también era inadmisible imaginar mujeres corriendo con polleras, pero a esto se le sumaba algo aún peor: un contacto físico indecoroso, la posibilidad de roce de la pelota con ciertas partes íntimas y la necesaria "violencia" que implicaba su posición y dominio.

Al igual que en el fútbol, los clubes ciclísticos que fueron conformándose tuvieron una nutrida agenda deportiva y social; era frecuente la organización de bailes, kermeses y espectáculos artísticos. En estas actividades, significativas para el desarrollo institucional y el fortalecimiento de lazos sociales e identitarios, fue importante la participación de las mujeres aunque nunca solas, sino como parte de un núcleo familiar en el que los varones eran "los deportistas".

¿Por qué hubo mujeres ciclistas y no mujeres futbolistas? A las cuestiones quealudimos más arriba debe agregársele una central: el fútbol no puede pensarse sin la competencia y el contacto físico, mientras que el ciclismo admite, además de las carreras, la posibilidad de paseos, excursiones y contacto con el entorno natural que se considera beneficioso para atemperar ánimos y moldear el carácter.

En el caso del esquí, tanto en Mendoza como en la Patagonia norte, su desarrollo acompañó la intención nacional de ocupación social de la cordillera, para potenciar la actividad turística de un nuevo espacio por dominar. Los objetivos de los clubes de esquí que se conformaron unieron naturaleza, paisaje, montaña, esquí para fortalecer la atracción de turistas.

Si bien el uso de tablas de madera a manera de esquíes es de antigua data en la zona cordillerana patagónica, el esquí como deporte es más tardío que el fútbol y el ciclismo ya que surge a partir de los años 1930. Otra particularidad es que irrumpe en las zonas urbanas de montaña en grupos sin tradición previa en esa práctica, lo que lo convierte en "novedad" en una actividad corporal exenta de prescripciones, prohibiciones y mandatos.

Mientras comparte con el ciclismo las bondades que provienen del contacto con la naturaleza, requiere para su ejercicio habilidades que no están reñidas con el ideal femenino: si bien la velocidad es importante, lo es más aún la habilidad técnica, la destreza de los movimientos y la estrategia. A esta cuestión se le suma el hecho de que la práctica del esquí fue -a medida que la actividad se afianzaba y se profesionalizaba- sinónimo de estatus social. Participar de las actividades de los clubes de esquí y de los eventos organizados en la montaña fue transformándose en una propuesta para grupos económicos medios-altos y altos, a medida que surgían equipamientos específicos -y caros- y medios de elevación mecánicos para acceder a la cima de los cerros.

Muchas familias enviaron a sus hijas a participar de las actividades que los clubes de esquí ofrecían en temporada invernal y en el verano -en este caso más vinculadas al goce de la montaña a través de excursiones y trekking-, en la convicción de que el rodearse con miembros de los grupos económicos más encumbrados -tanto de las comunidades locales como de la oligarquía porteña amante de este deporte- podría significar un ascenso social y la posibilidad de viajar a Europa al participar de competencias internacionales de esquí. A diferencia del ciclismo, en el que se observa una continuidad en la práctica entre abuelos, padres e hijos, en el caso del esquí sus practicantes no tienen trayectorias familiares previas en él.

En el contexto patagónico, los miembros nucleados en los clubes deportivos comparten junto al scoutismo la participación en conmemoraciones patrias y festejos locales. Torneos de fútbol y carreras de ciclismo formaron parte de la agenda de las comisiones de festejos de la 
región, y el desfile de scouts y deportistas transitaron en innumerables ocasiones las calles céntricas de pueblos y ciudades. Esa era la niñez y juventud que había que mostrar y que debía ser imitada: virilidad y feminidad encarnada en un cuerpo sano moral y físicamente.

\section{El scoutismo y sus mujeres}

En el caso del scoutismo, el perfil de la guía scout y sus posibilidades de intervención en el entorno natural y social estuvieron limitados por su condición de "mujer". La ayuda al prójimo, consigna baluarte de la filosofía scout, se resignificó en el caso de las mujeres por la premisa que ellas debían ser, en primer lugar, buenas madres para los futuros scouts, buenas docentes involucradas en su formación, buenas gestoras de fondos que garantizaran ayuda a los más necesitados, uniformes y salidas. La incorporación de niñas y jóvenes como scouts fue tardía, numéricamente menor, con propuestas de acción diferentes a las de los varones, y producto de la tenaz insistencia y militancia de algunas niñas y mujeres que bregaron por el ingreso a la Asociación Scout.

El scoutismo fue importantísimo en Patagonia, desde el año 1912 y en especial, a partir de la década de 1930. Al no existir una disposición oficial general, la incorporación de niñas al movimiento quedó al arbitrio de las comisiones directivas de los grupos. Mientras algunos aceptaron la incorporación de mujeres, en actividades diferenciadas de las de los varones con los que compartían algunos eventos, hubo grupos que se opusieron a su ingreso.

A niñas y jóvenes se les adjudicaban prioritariamente tareas propias del espacio doméstico y de prácticas de primeros auxilios, en consonancia con el destino vital que las aguardaba: amorosa esposa, abnegada hija y madre, formadora de futuros scouts. La naturaleza debía ser apropiada en forma diferenciada de acuerdo con la posición social, etaria o de sexo. Los aprendizajes propiciaban una relación más directa con el entorno natural en el caso de los varones -armado y uso de carpas, salvataje, técnicas de vigilancia y acecho, etc.--, mientras se protegía el decoro de las mujeres, alojadas en edificios (escuelas o comisarías por lo general), cuando se realizaban excursiones en las que debían pernoctar. En forma explícita, se prohibieron los campamentos mixtos.

A diferencia del scoutismo, el guidismo tenía entre sus funciones centrales preparar amas de casa y esposas, por lo que abundan interpelaciones y consejos en ese sentido. Las condiciones de una guía están claras: hay que poseer honor, ser útil y ayudar a otros, amiga de todos y hermana de toda guía, cortés, buena con los animales, obedecer órdenes, sonreír y cantar, ser económica, pura de pensamiento, palabra y obra. También se proponía la realización de trabajos manuales de costura, cestería, confección de muñecas y carpintería sencilla. La utilidad de adquirir este tipo de saberes tenía que ver con la preparación para el futuro.

En las conmemoraciones y los actos en los que participaban niñas scouts, les correspondían recitados y declamaciones, en muchos casos acompañados por acordes de piano y algunas demostraciones gimnásticas.

Patagonia fue escenario de visitas de niñas scouts provenientes de diferentes latitudes e incluso de Chile, pero no hubo presencia femenina en la treintena de asociaciones que se crearon desde Ushuaia hasta Neuquén hasta la década de 1950. Si bien la prensa y las comunidades locales recibían con beneplácito a niñas y jóvenes scouts que venían de visita, no las incluyeron en sus filas. Posiblemente, influyó en esta situación el hecho que la mayoría de los líderes y maestros scouts patagónicos provenían de los cuerpos policiales y del Ejército, instituciones en las que, por entonces, las mujeres no tenían cabida.

\section{CONSIDERACIONES FINALES}

Como ha ocurrido en otras dimensiones de la vida cultural y política de la Argentina de la primera mitad del siglo $\mathrm{xx}$, las mujeres ingresaron en las instituciones debido a su militancia, insistencia y lucha y una vez dentro de ellas, realizaron itinerarios diferenciados del varón.

Se fomentaron las prácticas deportivas que afirmaran los roles naturalmente asignados por la sociedad patriarcal. En general, eran los varones quienes tenían más posibilidades de entrenamiento y de procurar un modelo de cuerpo atlético, aunque las mujeres fueron partícipes de paseos y excursiones en bicicleta, salidas a la montaña y el esquí. Será recién en la década de 1940 cuando las mujeres comiencen a constituirse como "deportivas" e ingresan en la agenda de competencias locales y regionales, en especial en la práctica del tiro al blanco, esquí y básquetbol. 
Para el esquí, el scoutismo y el ciclismo, la geografía de la Patagonia se convirtió en motivo para estar alerta en su defensa, medio para generar patriotismo -a partir del conocimiento y la admiración de las bellezas naturales- y en lugar para regenerar a niños y jóvenes en oposición a los peligros emergentes de las grandes ciudades. El contacto con asociaciones scouts de otras latitudes, y las competencias deportivas nacionales y con Chile, permitieron construir sesgos de identidad local/regional a la vez que sentidos de pertenencia a la comunidad nacional.

Del fútbol no participaron, salvo como espectadoras. En el ciclismo lo hicieron con su grupo familiar, y en el esquí se les permitió incursionar en forma independiente, posiblemente en relación con el prestigio social asociado a esta práctica deportiva (en especial en la década de 1940), la posibilidad de viajes y contactos con sujetos vinculados a los grupos de poder.

Las niñas scouts ingresaron tardíamente al movimiento, y si bien compartieron con los varones los aprendizajes y desafíos que surgían del contacto con la naturaleza y el servicio al prójimo, en ellas se acentuaron las tareas vinculadas al cuidado, lo que daba prelación a roles y mandatos que se concebían como naturales.

Las prácticas corporales en su conjunto fueron apoyadas por la prensa regional, las autoridades militares y civiles. Se les reconocía que cumplían la función de pedagogización social, al moralizar a niños y niñas, pero con objetivos diferenciados: fortalecer los cuerpos y reforzar la virilidad en los varones y acentuar la vocación de esposas y madres en las mujeres.

En síntesis, las prácticas deportivas desplegadas en el espacio patagónico de la primera mitad del siglo fueron, como en el caso de la ciudadanía, prácticas generizadas. Reforzaron estereotipos y mandatos a la vez que permitieron en sus intersticios, y especialmente con el correr de las décadas, que las mujeres irrumpieran por placer en el espacio público, lo transitaran y conocieran, comenzaran a competir y se animaran a más.

\section{REFERENCIAS}

Archetti, E. (2003). Masculinidades. Fútbol, tango y polo en la Argentina. Buenos Aires: Antropofagia.

Armus, D.y Scharagrodsky, P. (2014). El fútbolen las escuelas y colegios argentinos. Notas sobre un desencuentro en el siglo Xx. En S. Rinke y D. Armus (coords.). Del football al fútbol/futebol. Historias argentinas, brasileras $\mathrm{y}$ uruguayas en el siglo xx. Cuadernos de Historia Latinoamericana (85-99). Madrid/Frankfurt: Edit. Iberoamericana-Vervuert.

Barrancos, D. (2007). Mujeres en la sociedad Argentina. Una historia de cinco siglos. Buenos Aires: Sudamericana.

Chiappe, M. (2015). “ $\mathrm{A}$ la pelota! Fútbol, popularidad y hombría. Entre la sociedad civil y la intervención estatal. Bariloche, 1920-1945". En L. Méndez y A. Podlubne (comp.). Tiempo de jugar, tiempo de aprender. Educación, museos y prácticas corporales en la Patagonia Norte. 1910-1955 (pp. 157-184). Buenos Aires: Prometeo.

Chiocconi, M. (2015). La trascendencia política del esquí. Una razón de Estado en la Argentina de la primera mitad del siglo xx. En L. Mendezy A. Podlubne. (comp.). Tiempo de jugar, tiempo de aprender. Educación, museos y prácticas corporales en la Patagonia Norte. 1910-1955 (185-212). Buenos Aires: Prometeo.

Di Liscia, M. (2004). Médicos y maestros. Higiene, eugenesia y educación en Argentina (1880-1940). En M. S. Di Liscia y G. N. Salto (eds.). Higienismo, educación y discurso en la Argentina, 1870-1940 (pp. 37-64). Santa Rosa: E.

Frydenberg, J. (2011). Historia social del fútbol: del amateurismo a la profesionalización. Buenos Aires: Siglo XXI.

Lagrange, F. (1894). La higiene del ejercicio en los niños y en los jóvenes (trad. Ricardo Rubio). Madrid: Librería de José Jorro.

Lavrin, A. (1998). Women, Feminism \& Social Change in Argentina, Chile and Uruguay, 1890-1940. Nebraska: University of Nebraska, Lincoln and London.

Méndez, L. (dir.). (2011), Cuerpo, educación y tiempo libre en la Norpatagonia 1884-1945. Rosario: Prohistoria.

Mosso, A. (1892). El miedo (trad. Madrid Moreno). Madrid: Librería de José Jorro.

Mosso, A. (1894). La educación física de la juventud seguida de la educación física de la mujer (trad. Madrid Moreno). Madrid: Librería de José Jorro.

Nari, M. (1995). La educación de la mujer (o acerca de cómo cocinar y cambiar los pañales a su bebé de manera científica). En Mora, 1, 31-45.

Nari, M. (2004). Políticas de maternidad y maternalismo político; Buenos Aires (1890-1940).Buenos Aires: Biblos. 
Palma, H. (2005). Gobernar es seleccionar. Historia y reflexiones sobre el mejoramiento genético en seres humanos. Buenos Aires: Jorge Baudino Ed.

Podlubne, A. (2015). Entre ruedas y pedales. Surgimiento de las prácticas ciclísticas en la región del Nahuel Huapi, 1930-1950. En L. Méndezy A. Podlubne (comp.). Tiempo de jugar, tiempo de aprender. Educación, museos y prácticas corporales en la Patagonia Norte. 1910-1955 (213-240). Buenos Aires: Prometeo.

Reyna, F. (2014). La prensa escrita como actor social de un modelo deportivo. Córdoba (Argentina), primeras décadas del siglo Xx. En S. Rinke y D. Armus (coords.). Del football al fútbol/futebol. Historias argentinas, brasileras y uruguayas en el siglo xx (pp. 49-66). Madrid/Frankfurt: Edit. Iberoamericana-Vervuert.

Romero, E. (1922). Concursos escolares de educación física. Buenos Aires: Cabaut y Cía.

Scharagrodsky, P. (comp.). (2008). Gobernar es ejercitar. Fragmentos para una historia de la educación física en Iberoamérica. Buenos Aires: Prometeo.
Scharagrodsky, P. (2014). Dime cómo te mueves y te diré cuál es tu "sexo". Discurso médico, educación física y diferencia sexual a finales del siglo XIX y principios del siglo xx en Argentina. En D. Barrancos, D. Guy y A. Valobra (eds.). Moralidades y comportamiento sexuales. Argentina (1880-2011) (pp. 73-94). Buenos Aires: Biblos.

Scharagrodsky, P. (2015) Los arquitectos corporales en la educación física y los deportes. Entre fichas, saberes y oficios (Argentina primera mitad del siglo $\mathrm{xx}$ ). Trabajos y Comunicaciones2).Recuperado de http://www.trabajosycomunicaciones.fahce.unlp. edu.ar/article/view/TyC2015n41a05._Consultado el 11 de noviembre de 2015].

Suriano, J. comp. (2000). La cuestión social en Argentina. 1970-1943. Buenos Aries: La Colmena. 